\title{
Bilateral Impalpable Testes: A Special Entity of Cryptorchidism
}

\author{
Tariq Abbas, Ahmed Hayati, Mansour Ali \\ Hamad General Hospital, Doha, Qatar \\ Email: tariq2c@hotmail.com, ahayati@hmc.org.qa,mali31@hmc.org.qa
}

Received July 24, 2012; revised August 25, 2012; accepted September 10, 2012

\begin{abstract}
Background: Cryptorchidism is one of the most common genitourinary disorders in young boys. About $1 \%-2 \%$ of boys at age of 1 year have an undescended testis (UDT); this disorder is unilateral in about $90 \%$ of individuals and bilateral in about 10\%. However, bilateral impalpable testes represent a special category that should be differentiated from anorchidism as well as male pseudohermaphroditism. We investigated whether bilateral impalpable testes with its inherent hormonal and genetic factors has different outcomes in terms of success of orchiopexies compared to unilateral impalpable testes. Methods: We retrospectively analyzed the demographic and clinical findings, as well as immediate and 6 month outcomes, in patients diagnosed with bilateral impalpable undescended testes between 2006 and 2010. Findings were reported after a minimum of 6 months from the last surgical intervention. Results: Nine patients underwent laparoscopy for bilateral impalpable testes, 7 of whom had testes in the region of the internal inguinal ring. The success rate after laparoscopic exploration and open orchiopexy was $60 \%$ while the success rate with unilateral impalpable testes was $63.3 \%$ in the same study. Conclusion: Although laparoscopy is extremely useful in both the diagnosis and treatment of patients with bilateral impalpable testes, laparoscopy should be preceded by careful cytogenetic and hormonal workup for this particular group of patients. We found that the success rates of laparoscopic management of bilateral and unilateral impalpable testes were similar, as shown by testicular size clinically sassed during serial postoperative outpatient visits.
\end{abstract}

Keywords: Bilateral Non-Palpable Testis; Laparoscopic; Intra-Abdominal; Cryptorchidism

\section{Introduction}

Cryptorchidism is one of the most common genitourinary disorders in young boys. About $1 \%-2 \%$ of boys at age 1 year have an undescended testis (UDT), with the disorder being unilateral in about $90 \%$ and bilateral in about $10 \%$ of cases [1-3]. Almost 20\% of undescended testes are non-palpable [4].

Among the methods used to evaluate and manage undescended testes are imaging modalities and various surgical procedures [5]. Over the past two decades, there have been changes in the surgical treatment of undescended testes.

However, bilateral impalpable testes represent a special category that should be differentiated from anorchidism as well as male pseudohermaphroditism. We investigated whether bilateral impalpable testes with its inherent hormonal and genetic factors has different outcomes in terms of success of orchiopexies compared to unilateral impalpable testes. This was shown by the assessment of testicular size clinically during serial postoperative outpatient visits.

\section{Methods}

Patients under 14 years of age undergoing laparoscopy for clinically diagnosed impalpable testes between January 2006 and December 2010 in our institution were included in the study (Figure 1). Their records were retrospectively reviewed. Factors recorded included patient age at operation, clinical and laparoscopic findings, operative interventions and outcomes. All patients were followed up in the outpatient clinic for at least 6 months.



Figure 1. Percentges of successful orchiopexies in our study in diffenrent groups. 
Prior to surgery, patients were examined under anesthesia to confirm that the testes were intra-abdominal. This was followed by laparoscopic exploration, including the insertion of a $5 \mathrm{~mm}$ port supra-umbilically using a closed technique and use of a $5 \mathrm{~mm} 0$ camera. Secondary 2 - $3 \mathrm{~mm}$ ports were placed under direct vision if required and a $2 \mathrm{~mm}$ atraumatic grasper was used. Initially, we tried to identify the testes, testicular vessels, and vas deferens and whether the internal inguinal rings (IIR) were open or closed.

A "high" position of the testis was defined as being above the external iliac vessels; orchiopexy for these patients consisted of a two-stage Fowler-Stephens procedure. A "low" intra-abdominal testis was usually managed by one-stage laparoscopic orchiopexy. Orchidectomy was performed on an atrophic testis accompanied by a contralateral normal testis.

All patients were routinely followed-up at our outpatient clinic. A procedure was defined as "successful” if it resulted in a palpable testis in the scrotum of similar or increased size.

\section{Results}

Between January 2006 and December 2010, 91 patients, including 9 with bilateral and 82 with unilateral impalpable testes, were scheduled for therapeutic and diagnostic laparoscopy, for a total of 100 testes. Average patient age at the time of the surgical intervention was 64.3 months.

We found that the total success of orchiopexy for all testes was $63.3 \%$. This success rate was achieved following laparoscopic exploration and open orchiopexy for testes in the region of the IRR, representing the most frequent finding in bilateral intra-abdominal testes in this series (78\%) (See Figure 1).

There were no complications from laparoscopy in the immediate or postoperative periods. No port site hernia was detected on follow-up.

\section{Discussion}

Testicular descent, although not yet fully understood, takes place in two different stages, starting during weeks 8 and 25 of gestation, respectively. Failure of the first phase of descent is rarer than failure of the second phase, with failure of the first phase resulting in an intra-abdominal undescended testis [6].

Cryptorchidism is one of the most common genitourinary disorders in young boys. Although the management of boys with palpable testes has been standardized, there are no formal guidelines for the management of boys with non-palpable testes [7].

Clinical examinations have shown that $80 \%$ of UDTs are palpable. Of these, $30 \%$ are located in the inguinal superficial pouch, $20 \%$ in the inguinal canal, and $45 \%$ in the upper scrotum, with only 5\% in the perineum or thigh. In contrast, the remaining $20 \%$ of UDTs are non-palpable and are located in the abdominal cavity $[8,9]$.

In peripubertal boys with nonpalpable testes, the presence of Sertoli cells is easily assessed by measuring serum inhibin B and/or AMH concentrations [10,11]. Inhibin $\mathrm{B}$ is undetectable in anorchid boys, but generally within the normal range in cryptorchid boys [12]. However, there are no significant differences in these concentrations between boys with unilateral and bilateral cryptorchidism [13].

Laparoscopy is currently the most reliable diagnostic modality in the management of impalpable testes. Laparoscopy can clearly visualize anatomy and provides information on which a definitive decision can be based [14].

The three main laparoscopic findings are an IAT, observed in $40 \%$ of patients, intra-abdominal blind-ending cord structures in $15 \%$ and cord structures entering the IRR in $45 \%$ [15].

We found that laparoscopic management yielded similar success rates in patients with bilateral and unilateral impalpable testes, as determined by testicular size.

\section{Conclusion}

In conclusion, laparoscopy in the management of bilateral impalpable testes should be preceded by careful cytogenetic and hormonal workup. Laparoscopic management yielded similar success rates in patients with bilateral and unilateral impalpable testes, as determined by testicular size.

\section{REFERENCES}

[1] D. D. Sweeney, et al., "Minimally Invasive Surgery for Urologic Disease in Children," Nature Clinical Practice Urology, Vol. 4, No. 1, 2007, pp. 26-38. doi:10.1038/ncpuro0677

[2] A. J. Swerdlow, et al., "Risk of Testicular Cancer in Cohort of Boys with Cryptorchidism," British Medical Journal, Vol. 314, 1997, pp. 1507-1511. doi:10.1136/bmj.314.7093.1507

[3] F. Hadziselimovic and B. Herzog, "Treatment with a Luteinizing Hormone-Releasing Hormone Analogue after Successful Orchiopexy Markedly Improves the Chance of Fertility Later in Life,” Journal of Urology, Vol. 158, No. 3, 1997, pp. 1193-1195. doi:10.1097/00005392-199709000-00130

[4] C. Esposito and V. Garipoli, "The Value of 2-Step Laparoscopic Fowler-Stephens Orchiopexy for Intraabdominal Testes," Journal of Urology, Vol. 158, No. 5, 1997, pp. 1952-1954. doi:10.1016/S0022-5347(01)64189-2

[5] F. El-Anany, et al., "Laparoscopy for Impalpable Testis: Classification-Based Management,” Surgical Endoscopy, Vol. 21, No. 3, 2007, pp. 449-454. doi:10.1007/s00464-006-9003-0 
[6] J. M. Hutson and M. C. C. Clarke, "Current Management of the Undescended Testicle," Seminars in Pediatric Surgery, Vol. 16, No. 1, 2007, 64-70.

[7] C. Esposito, et al., "Management of Boys with Nonpalpable Undescended Testis," Nature Clinical Practice Urology, Vol. 5, No. 5, 2008, pp. 252-260.

[8] J. M. Hutson, “Undescended Testes,” In: M. D. Stringer, K. T. Oldham and P. D. E. Mouriquand, Eds., Pediatric Surgery and Urology: Long-Term Outcomes, 2nd Edition, Cambridge University Press, Cambridge, 2006, pp. 652663. doi:10.1017/CBO9780511545757.052

[9] L. A. Baker, et al., "Cryptorchidism,” In: J. Gearhart, R. Rink and P. D. E. Mouriquand, Eds., Pediatric Urology, W.B. Saunders, Philadelphia, 2001, pp. 738-753.

[10] K. Kubini, et al., "Basal Inhibin B and the Testosterone Response to Human Chorionic Gonadotropin Correlate in Prepubertal Boys," The Journal of Clinical Endocrinology \& Metabolism, Vol. 85, No. 1, 2000, pp. 134-138. doi:10.1210/jc.85.1.134

[11] R. Rey, "How to Evaluate Gonadal Function in the Cryptorchid Boy. Lessons from New Testicular Markers,"
Journal of Pediatric Endocrinology \& Metabolism, Vol. 16, 2003, pp. 357-364. doi:10.1515/JPEM.2003.16.3.357

[12] N. Lahlou, "Marc Roger Inhibin B in Pubertal Development and Pubertal Disorders," Seminars in Reproductive Medicine, Vol. 22, No. 3, 2004, pp. 165-174.

[13] P. Christiansen, A. M. Andersson, N. E. Skakkebaek and A. Juul, "Serum Inhibin B, FS, LH and Testosterone Levels before and after Human Chorionic Gonadotropin Stimulation in Prepubertal Boys with Cryptorchidism," European Journal of Endocrinology, Vol. 147, 2002, pp. 95-101. doi:10.1530/eje.0.1470095

[14] S. Y. Tennenbaum, et al., "Preoperative Laparoscopic Localization of the Non Palpable Testes, a Critical Analysis of a 10-Year Experience,” Journal of Urology, Vol. 164, 2000, pp. 154-155.

[15] E. Mohamed, M. D. Hassan and M. D. Abdulrahim Mustafawi, "Laparoscopic Management of Impalpable Testis in Children, New Classification, Lessons Learned, and Rare Anomalies,” Journal of Laparoendoscopic \& Advanced Surgical Technique, Vol. 20, No. 3, 2010, pp. 265-269. 